\title{
Ciclos e estratégia
}

iclos econômicos são períodos caracterizados por crescimento ou recesso da economia de um país ao longo de um determinado período do tempo. Representam, para as empresas, oportunidades ou grandes ameaças. Por esse motivo, os empreendedores e gestores devem considerá-los no momento preciso em que forem elaborar ou revisar suas análises estratégicas. 0 artigo apresenta as influências desses ciclos sobre as diversas áreas estratégicas da empresa e destaca como esta pode lidar com a inflexibilidade das condiç̃̃es macroeconômicas por eles representadas.

por Carlos Osmar Bertero FG-EAESP

$\mathrm{Na}$ linguagem de economistas e do pessoal de mercado financeiro, falar em ciclo econômico tornou-se quase um lugar-comum. Trata-se de um dialeto que ressalta os altos e baixos pelos quais passa uma economia em um determinado período. Na verdade, os ciclos econômicos têm praticamente a mesma idade que as economias de mercado.
Seu surgimento é concomitante à introdução de um sistema de contabilidade em nível nacional, quando então se percebeu que a atividade de um sistema econômico não é homogênea, nem tampouco constante.

Sendo assim, fala-se hoje em períodos de altas taxas de crescimento, de outros com taxas menores e ainda de 
outros com estagnação ou recessão. $\mathrm{N}$ a linguagem técnica, referir-se a um ciclo é reconhecer que, na economia como um todo, há características que variam em conjunto, em um determinado período de tempo. Desse modo, uma recessão indicada por uma taxa negativa de crescimento nos informa, por exemplo, o quanto um dito sistema econômico regrediu, ou diminuiu, durante o período de um ano, ou o quanto de riqueza se perdeu.

Se falar em ciclos econômicos não representa exatamente uma novidade, talvez falar de ciclos econômicos e estratégia o seja. De fato, se analisarmos com cuidado muitas das atuais teorias de estratégia disponíveis, constataremos elementos importantes da teoria econômica em sua formulação. É de se supor, portanto, que variações em indicadores econômicos tenham impacto direto sobre as deliberações internas da empresa, como decisões de manobras de vital importância à sobrevivência do negócio. Este artigo analisa precisamente a relação entre macroambientes econômicos e sua influência sobre as definições estratégicas das organizações. investimento, expansão, contratações de pessoal e outras

ção da tecnologia e a conjuntura econômica. Mesmo assim, de que modo preciso a economia e seus ciclos ou variações de desempenho têm importância para a estratégia de uma empresa?

Um caminho para responder a essa questão é analisar a história recente das empresas e o modo como a variação de conjuntura foi recebida em cada área da empresa. $N$ ão há dúvida de que períodos economicamente favoráveis, com taxas de crescimento altas e sustentadas, levam as empresas também a um bom desempenho. Isso pode ser constatado pelo crescimento das empresas nas décadas que vão de 1945 até aproximadamente 1975 nos países centrais. Esse período revelou grande crescimento das empresas, medido em termos de aumento de vendas e conquista de parcela de mercado.

Comercial e financei ro. Estratégias de crescimento econômico real çam, geralmente, as estratégias da área comercial, vendas e marketing, na medida em que o esforço pela maximização de vendas leva a investimentos em ativo fixo, ao aumento do quadro de pessoal, ao crescimento de redes de fornecedores e distribuidores e à celebração de diversos tipos de parcerias.

Quando há uma reversão do crescimento, com uma estabilização ou recessão, embora os esforços da área comercial por vender persistam por algum tempo, ajustes são feitos, paralisando investimentos em expansão, como aumento de capacidade instalada e novos projetos. Se os picos do ciclo favorecem expansão e cres-

Ambiente externo e estratégia. A constatação empírica de que as empresas incluem, em seus modelos de gestão estratégica, a necessidade de monitorar o ambiente externo pode se encontrada tanto nas disseminadas análises do tipo SW OT quanto na preocupação de consultores e acadêmicos de estratégia ao falarem de um ambiente genérico onde se pede que o gestor considere o contexto político, as características da sociedade, os valores, a situa- cimento, real çando as estratégias da área comercial, os vales tendem a prestigiar as estratégias das áreas financeira e de operações.

A área financeira é a que representa mais diretamente na equipe diretiva de uma empresa os interesses do acionista, cujos objetivos são a maximização de seu investimento, seja por meio de dividendos, bonificações e especialmente de valor de mercado. A geração de valor para o 
acionista é o principal motor do CFO (Chief Financial O fficer) ou do principal executivo da área financeira. Crescer não gera necessariamente valor para 0 acionista. Pode até mesmo reduzir o valor. M uitas estratégias de expansão levam a um aumento de faturamento e de ativos controlados que não revertem necessariamente ao acionista sob a forma de valor de mercado ou dividendos. Uma administração de cúpula, formada pela diretoria e pelo conselho de administração, terá sempre presente a necessidade de atender aos interesses dos acionistas.

Todavia, em período de redução de crescimento, quando o cenário econômico deixa de ser favorável, a pressão pelo atendimento dos interesses do acionista se aguça. É necessário ter bom desempenho mesmo quando as condições econômicas não sejam necessariamente róseas. Não foi por acaso que a maioria dos critérios pelos quais se julga a qualidade de uma boa administração passaram a ser predominantemente financeiros. E isso ocorreu a partir do final da década de 1970, quando as taxas elevadas de crescimento que predominaram no pós-guerra terminaram.
Operações e pessoal. A área de operações também tem seus critérios real çados em épocas de vales. Embora a competitividade esteja sempre presente no universo da estratégia, ela pode acirrar-se quando o crescimento é limitado ou eliminado como opção estratégica. Se a ausência de crescimento leva à estagnação da demanda agregada para um ramo, a única alternativa para se aumentar vendas é pela conquista de mercado dos concorrentes. Isso leva a concorrência de preços, redução de margens de lucro, melhoria na qualidade etc.

Essa relação dinâmica explica ainda o aumento da importância das medidas e instrumentos desenvolvidos nos últimos 25 anos e que são predominantemente instrumentos para aumento da eficiência e da produtividade, sem desprezo de qualidade. Os resultados concretos têm sido uma verdadeira obsessão com redução de custos, "enxugamentos" e vendas de ativos pela adoção de terceirizações e quarteirizações.

Instrumentos atualmente integrados ao mundo do gestor, como reengenharia, BSC Balanced Score Card, custeio por atividade,

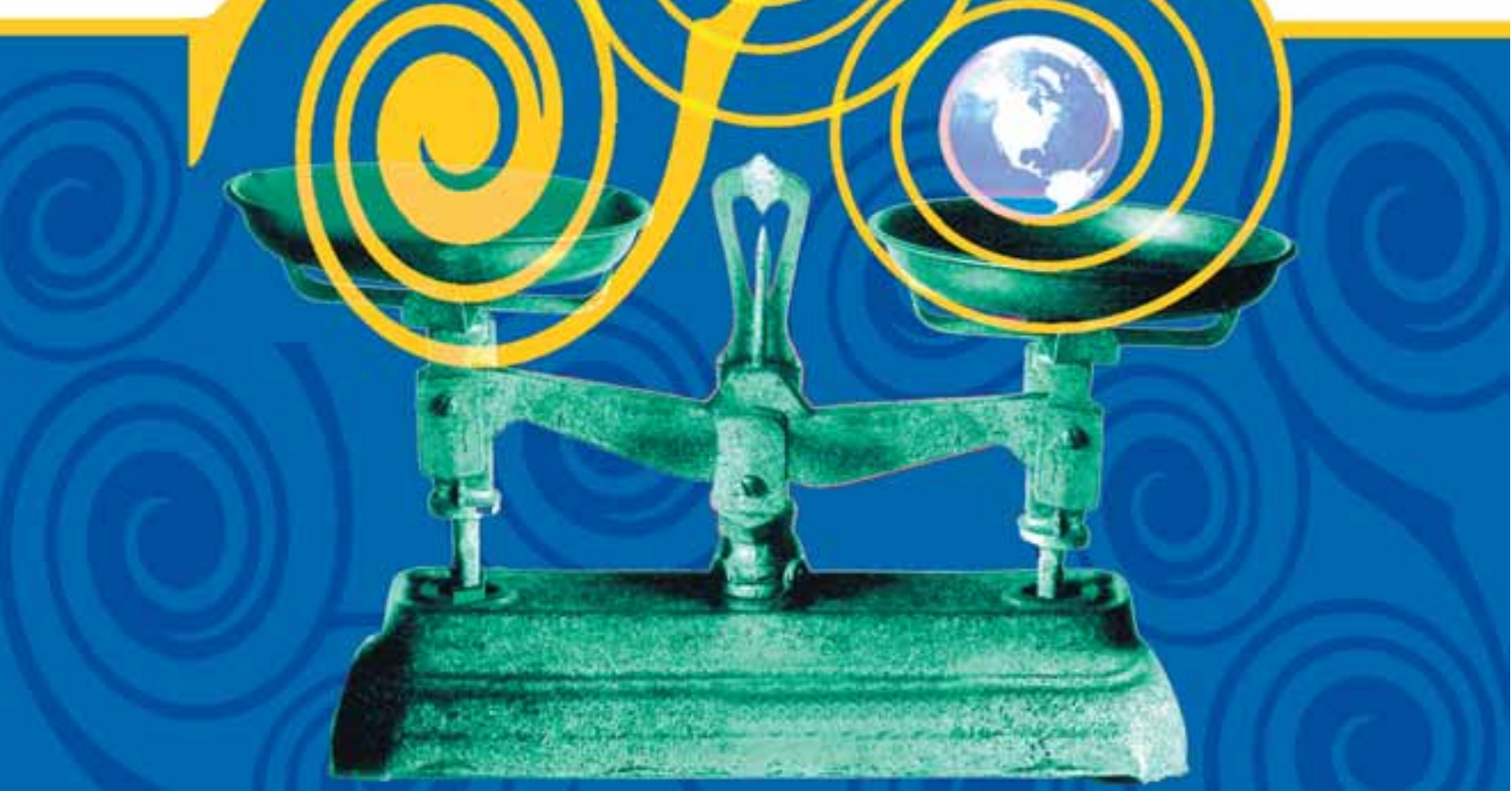


mudança organizacional e "restructuring", e a busca frenética por certificações as mais variadas teriam como denominador comum a busca da chamada excelência operacional. E esta teria repercussões em outras áreas, como gestão de pessoas e relações de trabalho. Boa parte dos problemas que hoje encontramos no mundo empresarial, como clima organizacional tenso, manifestações de insatisfação, insegurança e estresse, é conseqüência das medidas para aumento de eficiência e produtividade, que impõem inegável sobrecarga às pessoas.

Entre determinismo e espontanei dade. Uma segunda questão de especial rel evância entre ciclos econômicos e estratégia é o grau em que o primeiro, com seu determinismo característico, se choca com a dinâmica e a espontaneidade das decisões estratégicas. O u seja, como conciliar as inevitáveis condições dos ciclos econômicos e as formulações estratégicas dinâmicas, pensadas e espontâneas?

\section{Fatores políticos, acontecimentos}

\section{sociais, mudanças de costumes e de}

\section{valores, alterações no estilo de vida das}

\section{pessoas e a conjuntura econômica sempre}

\section{merecem atenção em procedi mentos de}

\section{formulação e revisão de estratégias.} io e longo. mente suas decisões e seu planejamento. Val es e picos dos ciclos econômicos de forma al guma devem desestimular empreendedor, pelo contrário.

A pesar de cada ciclo econômico ter suas próprias determinações e inflexibilidades, exigindo do estrategista a habilidade de reconhecer sua importância e impacto sobre as estratégias da empresa, ele não deve se submeter passivamente, aceitando de modo resignado um curso determinista. Para aju dá-lo, apresentamos a seguir al gumas recomendações para que 0 estrategista mantenha a consciência da importância dos ciclos, mas sem comprometer o desempenho de sua empresa nos prazos mé-

I dentifique oportuni dades. Não se deve transferir, mecânica e automaticamente, o ciclo para todos os ramos ou indústrias. Há momentos recessivos que podem ser benéficos a alguns ramos. Um exemplo seria o rescimento de ramos ligados ao entretenimento doméstico, que se expandiu mesmo em momentos de vales. $\mathrm{Na}$ verdade, a impossibilidade de buscar entretenimento fora de casa, por apertos no orçamento pessoal ou familiar, acaba fazendo com que TVs, DVDs e videocassetes sejam adquiridos para entretenimento em casa. Se a recessão aperta os orçamentos das classes média e baixa, mais do que os das classes de maior poder aquisitivo, entende-se que empresas possam redirecionar suas estratégias elegendo os segmentos de renda mais al ta como target.

De fato, assim como os seres vivos nascem, crescem e morrem, um ciclo econômico também possui sua seqüência natural de eventos, como o crescimento e a recessão. Essa seqüência é inevitável. Entretanto, a gestão estratégica trabal ha com o pressuposto do voluntarismo do estrategista. Em outras palavras, as diversas concepções de estratégia propõem que a visão, a missão e a vontade do empreendedor são características decisivas que fazem da estratégia um ato deliberado. Desse modo, o empreendedor luta contra a inércia e até mesmo contra as hostilidades do mercado e do ambiente externo, revendo continua-
Em nosso país, um produto relativamente novo como a telefonia móvel acabou gerando excelentes negócios para empresas que souberam explorar a inovação tecnológica do tel efone celular. As compras do tel efoninho têm superado os vales e atingido até mesmo as classes $C, D$ e E. Se um ramo for declinante, ou a estratégia de determinada empresa for equivocada, nem mesmo a maior explosão de crescimento trará bom desempenho. Não adianta insistir em fabricar carburadores depois que a injeção eletrônica foi criada e não há espaço para produzir em massa relógios mecânicos que ficaram reduzidos a um mercado de nicho. 
Aproveite os picos. Se os vales devem ser temidos e deve-se precaver contra eles, já os picos beneficiam, senão a todos, pelo menos a quase todos. Q uando um período de crescimento se apresenta, especial mente se for possível confiar que seja sustentável por tempo razoável, eis o momento para tocar estratégias de prazo mais longo, de nos prepararmos para expansão de demanda e para poder planejar 0 crescimento. Só não se beneficiarão de uma expansão os que realmente estiverem atados a estratégias equivocadas e até mesmo com problemas operacionais que podem criar obstáculos à execução de qualquer estratégia.

Mire no mercado. 0 foco no ciclo não deve nunca permitir que se descuide do centro das estratégias competitivas, ou seja, do mercado. É nele que se encontram nossos clientes, atuais e potenciais, e nossos concorrentes. A importância do ambiente externo genérico éinegável. $\mathrm{Ne}$ nhum gestor pode deixar de se ocupar dele. Fatores políticos, acontecimentos sociais, mudanças de costumes e de valores, alterações no estilo de vida das pessoas e, como colocado ao longo deste artigo, a conjuntura econômica sempre merecem atenção em procedimentos de formulação e revisão de estratégias.

Mas enquanto a importância da dimensão externa da estratégia pode variar entre os diversos fatores e na dependência do momento, o mercado é sempre importante. A relevância da conjuntura política pode ser de grande importância em alguns países e de nenhuma em outros. Que importância se deve atribuir ao fator político para quem tem negócios na Suíça? 0 mesmo não pode ser dito se vocêconsidera países como China, Cuba, Rússia e mesmo o Brasil. 0 mercado permanece sempre. Em qualquer momento e independentemente do lugar que seja objeto de esforços de gestão estratégica.

Conheça seu ramo. Ramos ou indústrias podem ser classificados de várias maneiras. É comum tratá-los a partir da aplicação do conceito de ciclo de vida do produto. Assim como produtos nascem, envel hecem e decaem, os ramos também seguiriam o mesmo itinerário. Isso leva a que se fale de ramos jovens, ramos maduros e ramos declinantes. Haveria, conseqüentemente, uma estratégia adequada para cada ramo.
Embora o ciclo econômico deva ser sempre considerado, nenhum gestor pode deixar de refletir sobre as características do ramo em que atua, o que implica saber se o ramo é jovem e ainda em fase de consolidação, com as turbulências próprias da juventude, ou se é um ramo maduro. Nesse caso, mudanças bruscas em produtos, tecnologias, principais players e market share são pouco prováveis. Quando tais mudanças ocorrem, isso se dá de maneira gradual. Essas características podem ser às vezes mais importantes do que uma fixação em tendências econômicas e perspectivas de crescimento ou recessão.

Estreitamenteligada às características eà idade de um ramo estão as tendências que ele apresenta. No mercado brasileiro, em vários ramos o que justifica presença e investimentos é a crença em tendências de crescimento futuro. 0 que levou montadoras a investirem para fabricar no Brasil em meados da década passada foi a crença de que a demanda por veícul os fosse crescente e que aqui se poderia instalar uma plataforma para exportação para outros países sul-americanos. Igualmente, um bom número de bancos estrangeiros foi atraído para o varejo bancário brasileiro pela crença de que a tendência era de inevitável expansão, dado o número relativamente pequeno de pessoas "bancarizadas" no país.

Outros exemplos da importância de tendências e perspectivas de um ramo podem ser encontrados em ramos particularmente angustiantes. 0 petróleo éum deles. Sabe-se hoje que os estoques de petróleo do planeta são fixos. Há unanimidade sobre o término do petróleo como combustível e fonte de energia. Há divergências sobre 0 prazo em que isso ocorrerá, mas as conseqüências são decisivas para todos, especialmente para empresas petrolíferas, petroquímicas e as demais envolvidas com energia em geral. Daí por que empresas de petróleo têm desenvolvido técnicas de planejamento de longo prazo e de prospecção sobre o seu próprio futuro.

Carlos Osmar Bertero

Prof. do Departamento de Administração Geral e Recursos Humanos da FGV-EAESP

Doutor em Administração pela Cornell University

E-mail: cbertero@fgvsp.br 